\title{
THERMOELECTRIC-DRIVEN AUTONOMOUS SENSORS FOR A BIOMASS POWER PLANT
}

\section{A. Rodríguez, D. Astrain, A. Martínez, E. Gubía, F.J. Sorbet}

Mechanical, Energy and Materials Engineering Department

Public University of Navarre, 31006 Pamplona, Spain

Tel: +34948169295 Fax: +34948 169099, e-mail: antonio.rodriguez@ unavarra.es

\begin{abstract}
This work presents the design and development of a thermoelectric generator intended to harness waste heat in a biomass power plant, and generate electric power to operate sensors and the required electronics for wireless communication.

The first objective of the paper is to design the optimum thermoelectric generator to harness heat from a hot surface, and generate electric power to operate a flowmeter and a wireless transmitter. The process is conducted by using a computational model, presented in previous papers, to determine the final design that meets the requirements of electric power consumption and number of transmissions per minute.

Finally, the thermoelectric generator is simulated to evaluate its performance. The final device transmits information every five seconds. Moreover, it is completely autonomous and can be easily installed, since no electric wires are required.
\end{abstract}

Keywords: Thermoelectric generation, waste heat, autonomous sensor, thermal Resistance

\section{Introduction}

Mankind has been utilizing renewable energy sources (including solar, wind and water) since ancient times until the arrival of the industrial revolution, when, due to low 
oil prices, they were virtually abandoned. In recent years, rising prices of fossil fuels and environmental problems of nuclear power plants are boosting a revival of renewable energy. Along with that, a new mentality on energy management is arising, focused on efficiency, sustainability and the promotion of decentralized energy production.

Although energy production mainly involves high power generation (MW), there are also research lines on low power generation $(\mathrm{kW}$ and $\mathrm{W})$. Proofs of this fact are all the small appliances and electronics not connected to the electric grid, such as mobile phones, audio devices, radios, etc., which require batteries to operate. The problems concerning these batteries have much to do with their limited life and the use of certain chemicals proven harmful to the environment.

The application of thermoelectric technology to these devices is increasing in importance, so that conventional batteries are been replaced for small, cheap and efficient thermoelectric generators. As an example, one of the pioneering applications of this technology dates back to the eighties [1] and involved the use of heat emitted by the human body to power a wristwatch using thermoelectric technology. The biggest drawback was the excessive hardness and brittleness of this device, typical of semiconductor materials. This disadvantage seems to be solved now with the inclusion of thin-film thermoelectric generators, more flexible and compact. Other applications use solar energy [2] or heat produced in the decomposition of small amounts of radioactive isotopes [3].

This work studies and develops a thermoelectric generator to harness waste heat in a biomass power plant, specifically hot surfaces at temperatures below $150{ }^{\circ} \mathrm{C}$, and generate electric power to operate sensors and the required electronics for wireless communication. Waste heat is a permanent source of wasted energy not used in any subsequent process. 
The thermoelectric generator is composed of several modules ENERKIT SC-12710-15 [4], arranged thermally in parallel and connected electrically in series, which harness heat from a heat source attached to them, transform part of it into electric power, and emit the rest to the environment through a finned dissipator. In this paper, finned dissipators with natural convection are used.

A mathematical model that simulates the operation of a thermoelectric generator, developed by our research group [5-7], is used as a design and optimization tool along this work. This computational model includes the effect of the heat exchangers, which allows us to consider the complex interactions between heat flows. Moreover, it considers the influence of the electrical load resistance, so we can determine the currentvoltage curves provided by the thermoelectric generator. These curves allow us to develop the required electronics for the thermoelectric modules, so that they work at matched load resistance and provide the maximum electric power.

\section{$\underline{\text { 2. Hot points and sensors in the biomass power plant }}$}

First of all, it is necessary to survey the thermodynamic cycle of the biomass power plant in order to know all the hot potential points where it might be interesting to install the thermoelectric generators. Only after analyzing both the surface and the available temperature at every point, one can provide the optimal locations for application.

The plant presents $25 \mathrm{MW}$ of installed power, working around 8000 hours per year with biomass (straw) consumption of 160,000 tons per year. 


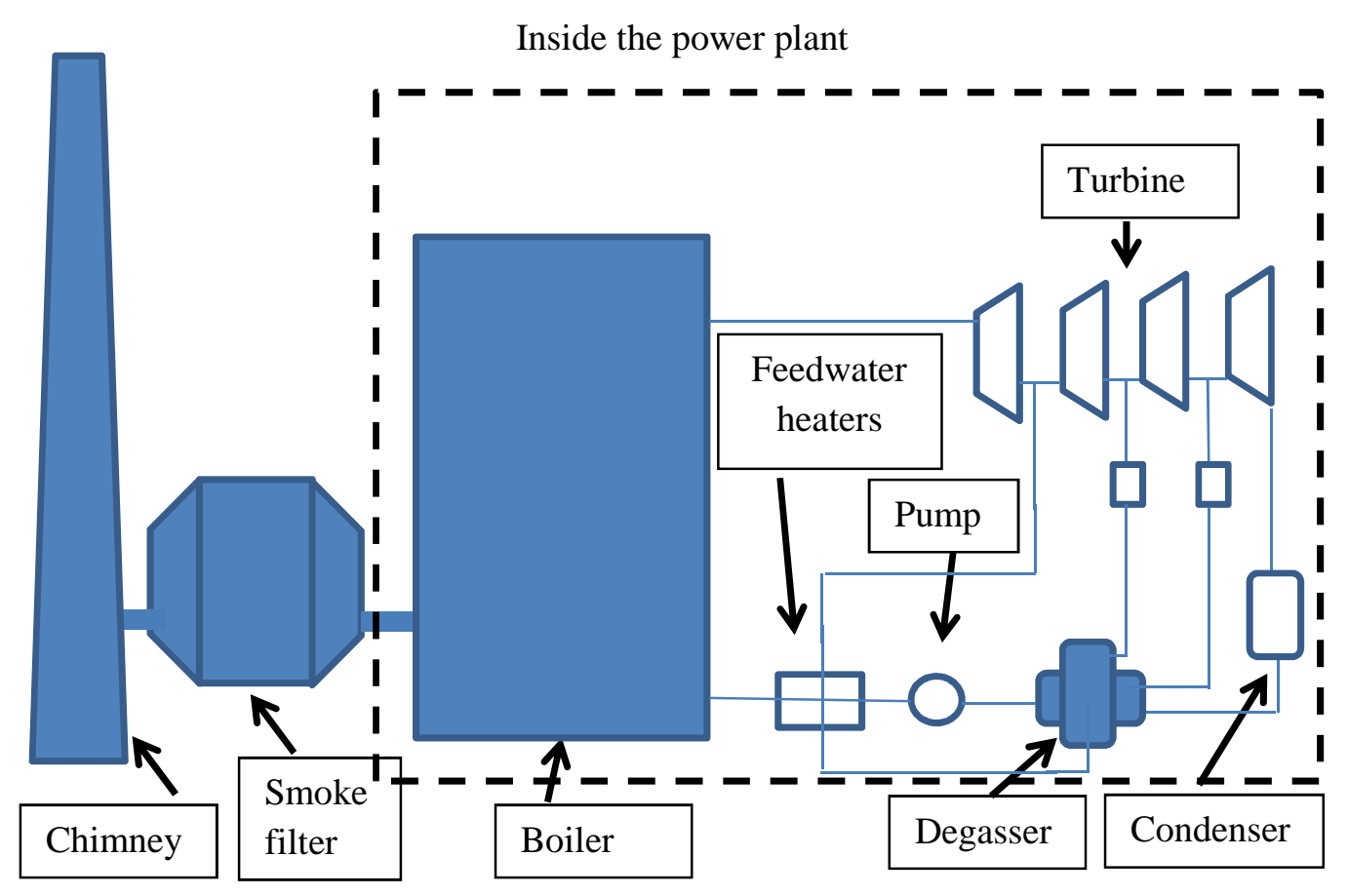

Figure 1 Scheme of the biomass power plant

Figure 1 shows a schematic view of the steam cycle. This is typical a Rankine cycle that converts heat energy from the combustion of biomass into work. The Rankine cycle uses water as working fluid. The energy supplied by the combustion produces watervapor in a high-pressure boiler. Then, the vapor is expanded in the turbine to generate mechanical work. After that, the low-pressure steam from the turbine goes through a heat exchanger where it becomes liquid after transferring heat to a cooling stream from a nearby river. Subsequently, a pump increases the pressure of the fluid and guides it back into the boiler, thus closing the cycle. Apart from these basic components, there exists auxiliary equipment that increases the efficiency of the installation, such as preheaters, degassers, etc. For proper operation, the plant also uses a large number of sensors (pressure, temperature, flow, $\mathrm{pH}, \ldots$ ) that require electric power to operate, supplied by batteries or the electric grid through wires. Our design of thermoelectric generator intends to remove both the batteries and the wires. 
The most important factors when selecting a hot point are the accessibility, the hot temperature and the environment temperature. Moreover, the installation of the thermoelectric device must not affect the normal operation of the plant.

After analyzing both the Rankine cycle of the power plant and all the sensors, we concluded that the most interesting hot points to install thermoelectric generators are the following four:

- Smoke Filter: Exhaust gas at $140{ }^{\circ} \mathrm{C}$ from the combustion boiler enters the filter, which removes the solid particles, before going up the chimney.

- Chimney: At the top of the chimney, exhaust gas is at $140{ }^{\circ} \mathrm{C}$.

- Ignition air flow: Close to the boiler, this air heats a surface at $100^{\circ} \mathrm{C}$.

- Degasser: This component can be found just before the pump that leads to the boiler. The fluid inside is at about $185^{\circ} \mathrm{C}$, so that the attaching surface is at around $150{ }^{\circ} \mathrm{C}$.

Table 1 shows approximate values of the maximum electric power produced by the generator $\left(\mathrm{W}_{\mathrm{TEG}}\right)$ at different hot points of the plant (final results from Table 3 ). Then, the heat flow transferred from the hot point to the generator is provided by Eq. (1), where the efficiency $\left(\varepsilon_{\mathrm{TEG}}\right)$ is considered to be around of $3 \%$, usual value for this kind of thermoelectric generators [8-10].

$\dot{Q}_{h}=\dot{W}_{T E G} / \varepsilon_{T E G}$

Then, Eq. (2) provides the temperature drop in the corresponding fluid (steam, air or exhaust gas) due to the heat transferred to the thermoelectric generator, being the mass flow $\left(\dot{\mathrm{m}}_{\mathrm{i}}\right)$ and specific heat $(\mathrm{cp})$ of the different fluids indicated in Table 1.

$\Delta T_{i}=\dot{Q}_{h} / c_{p} \dot{m}_{i}$ 


\begin{tabular}{|c|l|l|c|c|}
\hline & $\begin{array}{l}\text { Smoke } \\
\text { filter }\end{array}$ & Chimney & $\begin{array}{l}\text { Ignition air } \\
\text { flow }\end{array}$ & Degasser \\
\hline$\dot{W}_{T E G}[\mathrm{~W}]$ & 1,8 & 1,8 & 1,2 & 2 \\
\hline$\dot{Q}_{h}[\mathrm{~W}]$ & 60 & 60 & 40 & 66,7 \\
\hline$\dot{m}_{i}[\mathrm{~kg} / \mathrm{s}]$ & 36 & 36 & 36 & 30 \\
\hline$c_{p}[\mathrm{~J} / \mathrm{kgK}]$ & 1002,4 & 1002,4 & 1002,4 & 4181,3 \\
\hline$\Delta T_{i}[\mathrm{~K}]$ & $1,6 \cdot 10^{-3}$ & $1,6 \cdot 10^{-3}$ & $1,1 \cdot 10^{-3}$ & $5 \cdot 10^{-4}$ \\
\hline
\end{tabular}

Table 1 Temperature drop of the working fluid, $\Delta \mathrm{T}_{\mathrm{i}}$, for different configurations

In all the cases, the mass flow rate of the fluid is high enough not to be influenced by the thermoelectric generator, so that the temperature of each hot point can be considered constant.

The environment temperature inside the power plant ranges from $20^{\circ} \mathrm{C}$ in winter to $40{ }^{\circ} \mathrm{C}$ in summer; outside, it ranges from 0 to $30^{\circ} \mathrm{C}$.

Measurement equipment and sensors currently used in the power plant, and suitable to be connected to the thermoelectric generator, are the following:

- Flowmeter FV4000 and transmitter 10VR1311 AK45A32 A1A, ABB (combined load resistance of $650 \Omega$ )

- TH02-Temperature Transmitter with Pt100 V11518-1301, ABB (combined load resistance of $600 \Omega$ )

- $\quad \mathrm{pH}$ Transmitter PH402G/U of Yokogawa (combined load resistance of $550 \Omega$ )

In Fig. 2, one can see the possible integration of the thermoelectric generator on the surface of the chimney and the degasser. 


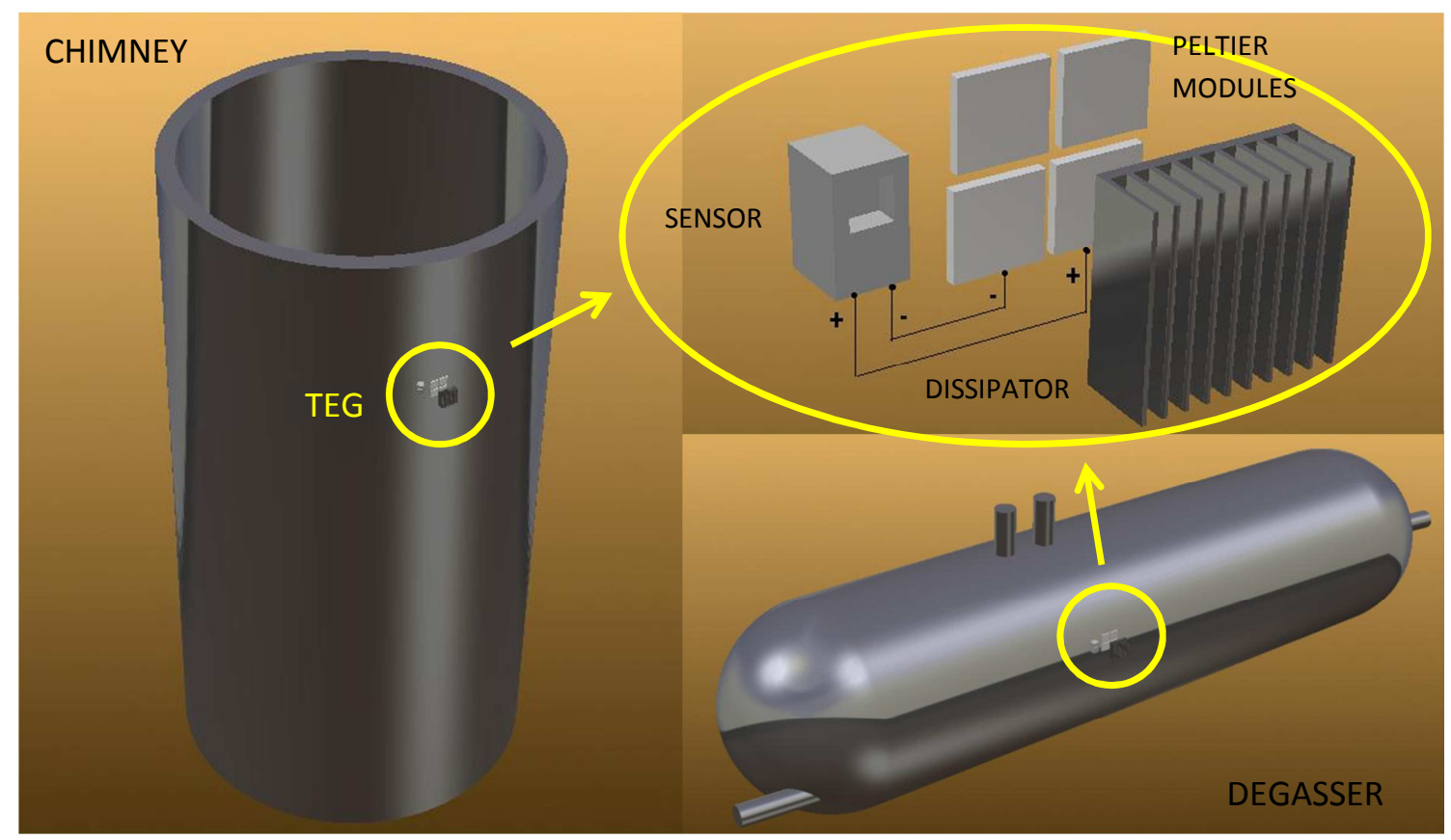

Figure 2. TEG localization in different components of the plant

\section{Computational method and methodology}

The objective of this section is to determine the influence of the dissipator thermal resistance and the number of modules on the electric power produced by the thermoelectric generator, in order to select the optimal configuration. Simulations provide the cited influence, which will lead to the construction of different prototypes in subsequent papers.

The load resistance connected to the thermoelectric modules has also strong influence on the electric power generated. Maximum power is achieved at half the opencircuit voltage, which occurs when the load resistance is equal to the internal resistance of the modules. The simulations consider load resistances from 0 to $1000 \Omega$.

\subsection{Computational model}

The computational model developed by our research group [5-7] requires as input parameters the temperatures of the hot point and the environment (hot and cold reservoirs), as well as the thermal resistances and thermal capacities of the components 
of the thermoelectric generator. No other experimental temperatures are required. Then, the model determines all the heat flows and temperatures of these components, as well as the efficiency, voltage, electric current and electric power generated.

The model solves the non-linear set of equations composed of the Fourier's law and the thermoelectric effects, namely Seebeck, Peltier, Joule and Thomson, all of them temperature-dependant, using the finite differences method. This method requires the reduction of the whole system into a mesh of representative nodes, each one connected to the surrounding nodes by thermal resistances. Likewise, each node has a thermal capacity that sets the variation rate of its temperature. This method replaces the threedimensional Fourier's Law with the corresponding implicit finite-differences expression, provided by Eq. (3), which must be applied to all the nodes of the system [5-7].

$-\frac{T^{\prime}{ }_{i-1} \delta \tau}{C_{i} R_{i-1, i}}+T^{\prime}{ }_{i}\left[\frac{\delta \tau}{C_{i}}\left(\frac{1}{R_{i-1, i}}+\frac{1}{R_{i, i+1}}\right)+1\right]-\frac{T^{\prime}{ }_{i+1} \delta \tau}{C_{i} R_{i, i+1}}=T_{i}+\frac{\dot{Q}_{i} \delta \tau}{C_{i}}$

The discretization of the thermoelectric generator uses symbols of an electric analogy, as can be seen in Fig. 3. The hot reservoir, the cold reservoir and the dissipator are represented by a single node each, whereas the thermoelectric modules require a series of nodes to obtain accurate results. The thermal resistances between connected nodes $\left(\mathrm{R}_{\mathrm{i}, \mathrm{i}+1}\right)$ and the thermal capacities $\left(\mathrm{C}_{\mathrm{i}}\right)$ are input parameters of the model, both of them depending on the geometry and the thermal properties of the components, which points out that the model is a tool for design and optimization.

The computational model calculates temperatures for instant of time $(\tau)$, updates the corresponding thermal resistances, thermal capacities and heat flows, and finally calculates temperatures for instant of time $(\tau+\delta \tau)$. Every step represents a real state of 
the system, which points out that the model is capable of simulate both steady and transitory states. It should be noted that the model is deterministic, since no randomness is included in the input parameters.

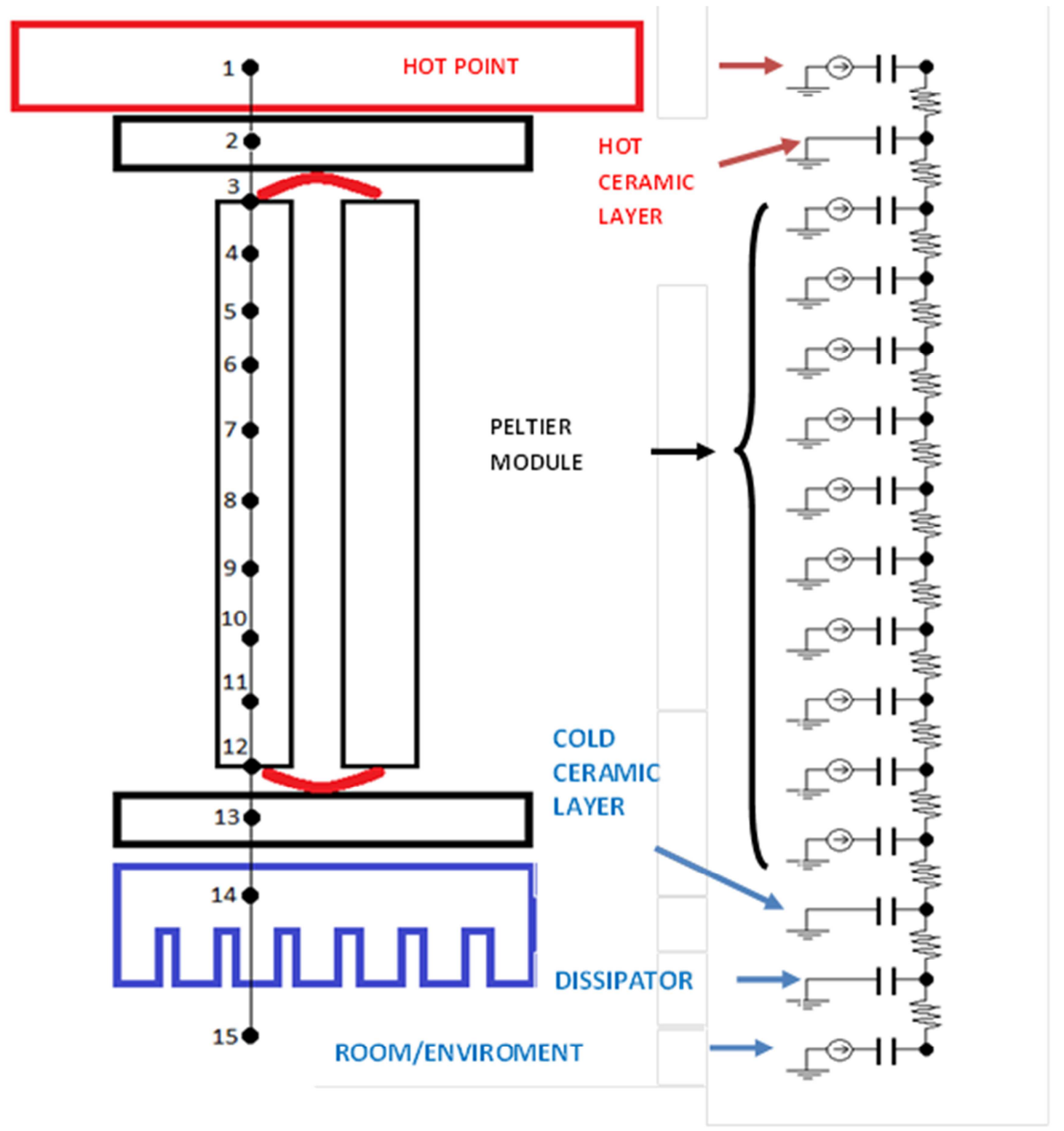

Figure 3 Scheme of the thermal-electric analogy of the computational model.

All the input parameters can be easily modified, thus allowing the simulation of a huge variety of cases. The input parameters are classified into the following groups: thermoelectric module design (materials and geometry), thermal resistance of the 
dissipator, electrical load resistance, temperatures at the cold and hot reservoir, and number of modules.

The output variables are: temperature of each node, heat flows produced by the thermoelectric effects and transferred between nodes, voltage, electric current and electric power generated, all of them provided as functions of time.

\subsection{Simulation results}

\section{a. Influence of the thermal resistance of the dissipator}

Figure 4 shows the influence of this thermal resistance $\left(R_{d}\right)$ and the load resistance $\left(\mathrm{R}_{1}\right)$ on the electric power generated by 4 thermoelectric modules (each one presents an electric internal resistance of $4 \Omega$ and is composed of 127 pairs), given a temperature difference of $80{ }^{\circ} \mathrm{C}$ between the hot and cold reservoirs. This temperature difference can be assumed constant as was demonstrated in Table 1.

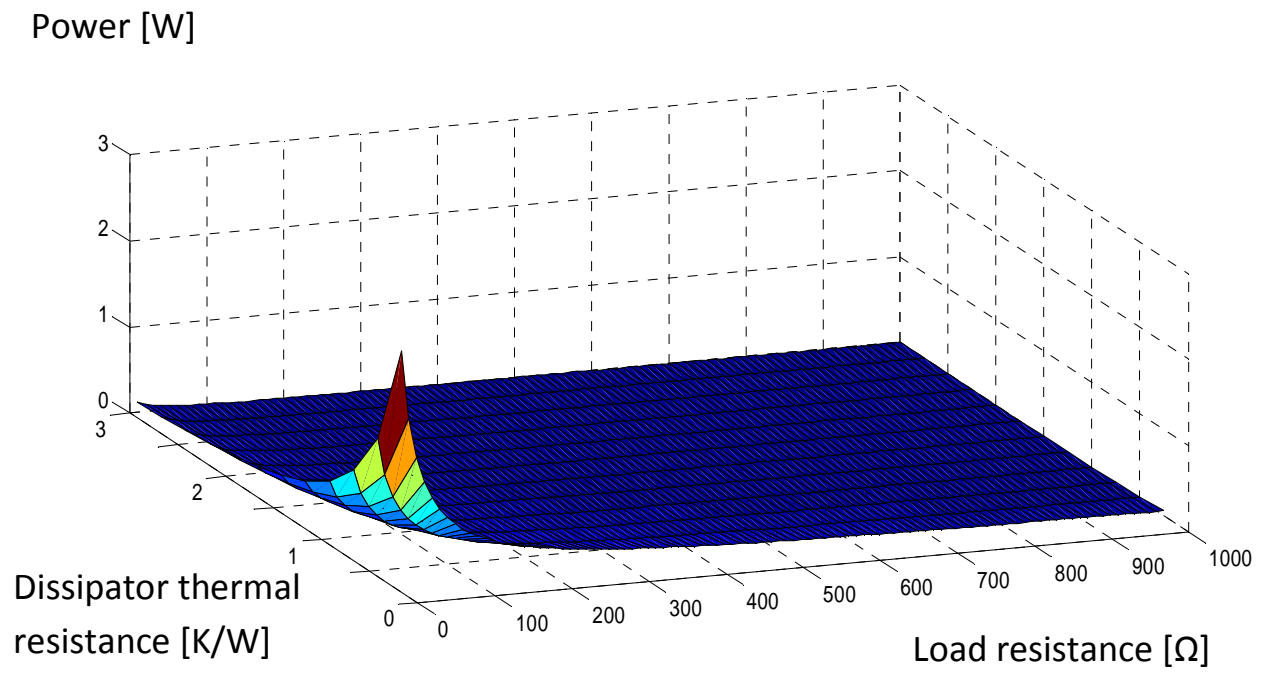

Figure 4 Power generated as a function of the $R_{d}$ and $R_{1}$

This figure shows that the electric power drops dramatically when the thermal resistance of the dissipator increases a little bit. The same applies to the load resistance, with less significant influence, though. These simulations show that the electric power 
increases as the load resistance approaches the internal resistance of the four modules connected in series, so that the voltage approaches half the open-circuit voltage, as explained before.

In conclusion, for a thermal resistance of the dissipator above $1.5 \mathrm{~K} / \mathrm{W}$, the electric power is reduced by more than $75 \%$ with respect to that obtained with the best thermal resistance $(0.23 \mathrm{~K} / \mathrm{W})$, and the application is not feasible. The load resistance has also great influence on the electric power, but this is a design parameter imposed by the internal electrical resistance of the sensor and the corresponding transmitter.

\section{b. Influence of the number of thermoelectric modules}

Figure 5 shows the influence of the number of thermoelectric modules (from 1 to 4 ) on the electric power produced by the thermoelectric generator, given a temperature difference of $80{ }^{\circ} \mathrm{C}$ between the hot and cold reservoirs. A finned dissipator with base area of is proposed. Computational-fluid-dynamics software "Ansys-Fluent" provides its thermal resistance as a function of the number of modules, being $0.92 \mathrm{~K} / \mathrm{W}$ when only one module is installed. Many examples of this methodology are easily found in the literature [11]. Then, each module is considered to have its own $81 \times 81 \mathrm{~mm}^{2}$ dissipator with $0.92 \mathrm{~K} / \mathrm{W}$ of thermal resistance. Therefore, if four modules were installed, the equivalent thermal resistance would be $0.23 \mathrm{~K} / \mathrm{W}$, as Fig. 6 , on the right, points out. 


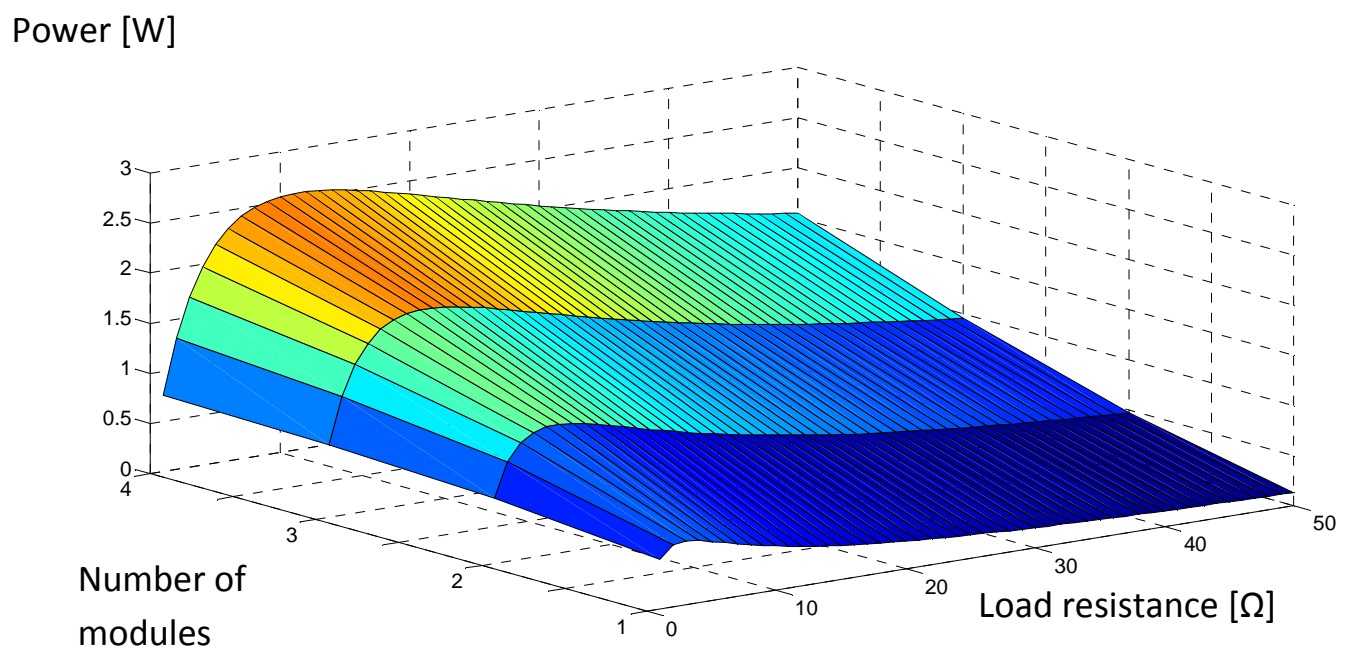

Figure 5 Power generated as a function of the number of modules and $R_{l},\left(R_{d}=0.23 K / W\right)$.

The electric power rises with the increasing number of modules, which seems obvious since the temperature difference between the hot and cold reservoirs keeps constant. Likewise, the maximum power is reached when the load resistance matches the internal resistance of the modules, which increases from 4 to $16 \Omega$ as the number of modules increases from 1 to 4.

Although installing a dissipator per module improves significantly the electric power generated, it also increases both the cost and the required space, which may be constricted inside the power plant. Then, a second option would be to install a single dissipator for all the modules, as can be seen in the central picture of Fig. 6. Again, a finned dissipator with base area of $81 \times 81 \mathrm{~mm}^{2}$ is proposed. A similar methodology to that used in the previous case [11] points out that the thermal resistance of the dissipator turns out to be $0.70 \mathrm{~K} / \mathrm{W}$ when four modules are installed, which is significantly higher than that obtained for four modules and four dissipators $(0.23 \mathrm{~K} / \mathrm{W})$ but slightly lower than that for one module and one dissipator $(0.92 \mathrm{~K} / \mathrm{W})$. Two reasons explain this fact: On one hand, given a fixed dissipator, the thermal resistance per module increases as the number of modules increases, since the dissipation area per module also decreases. On 
the other hand, as the number of modules increases, the effect of constriction on the heat transfer from the modules to the dissipator causes a reduction in the thermal resistance of the dissipator [12], since the modules cover almost all the base area of the dissipator and the heat flow is more evenly distributed along this surface.

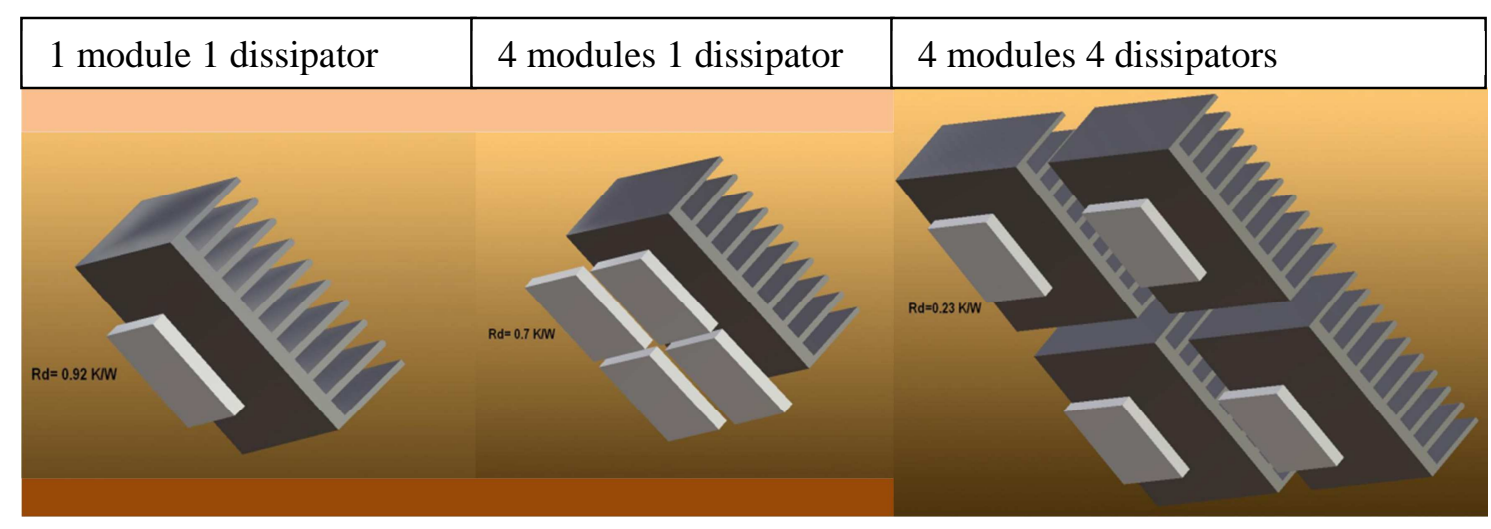

Figure 6 Configurations proposed for the dissipator

As a result, Fig. 7 indicates that the electric power still rises with the increasing number of modules but not as abruptly as it did in the case presented in Fig. 5. In that case, the maximum electric power of four modules reached $2.5 \mathrm{~W}$, whereas it hardly reaches $1 \mathrm{~W}$ now. This fact makes evident the great importance of the thermal design and heat transfer management in thermoelectric generators.

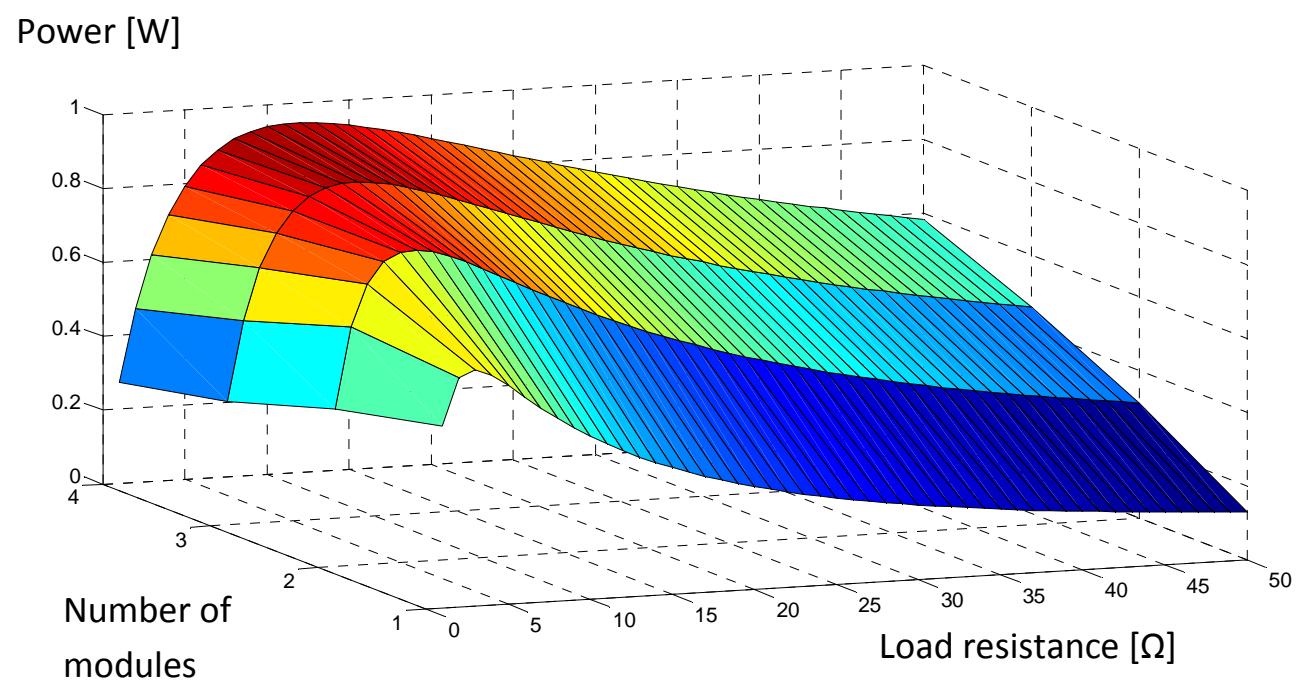

Figure 7 Power generated as a function of the number of modules and $\mathrm{Rl},(\mathrm{Rd}=0.7 \mathrm{~K} / \mathrm{W})$. 


\section{Selected case}

The proposed prototype of thermoelectric generator can include from 1 to 4 thermoelectric modules and a finned dissipator with base area of $81 \times 81 \mathrm{~mm}^{2}$. Its thermal resistance varies again from 0.70 to $0.92 \mathrm{~K} / \mathrm{W}$, depending on the number of modules. The selected sensor is a flowmeter Vortex FV4000 with its corresponding transmitter ELSELMA TXA15101E, presenting a combined load resistance of $650 \Omega$, which is quite high compared to the internal resistance of the modules. This is the reason why the electric power presented in Fig. 8 is an order of magnitude lower than the maximum presented in Figs. 5 and 7. Likewise, Table 2 shows the electric power for some specific temperature differences between the hot and cold reservoirs that can be found in the biomass power plant.

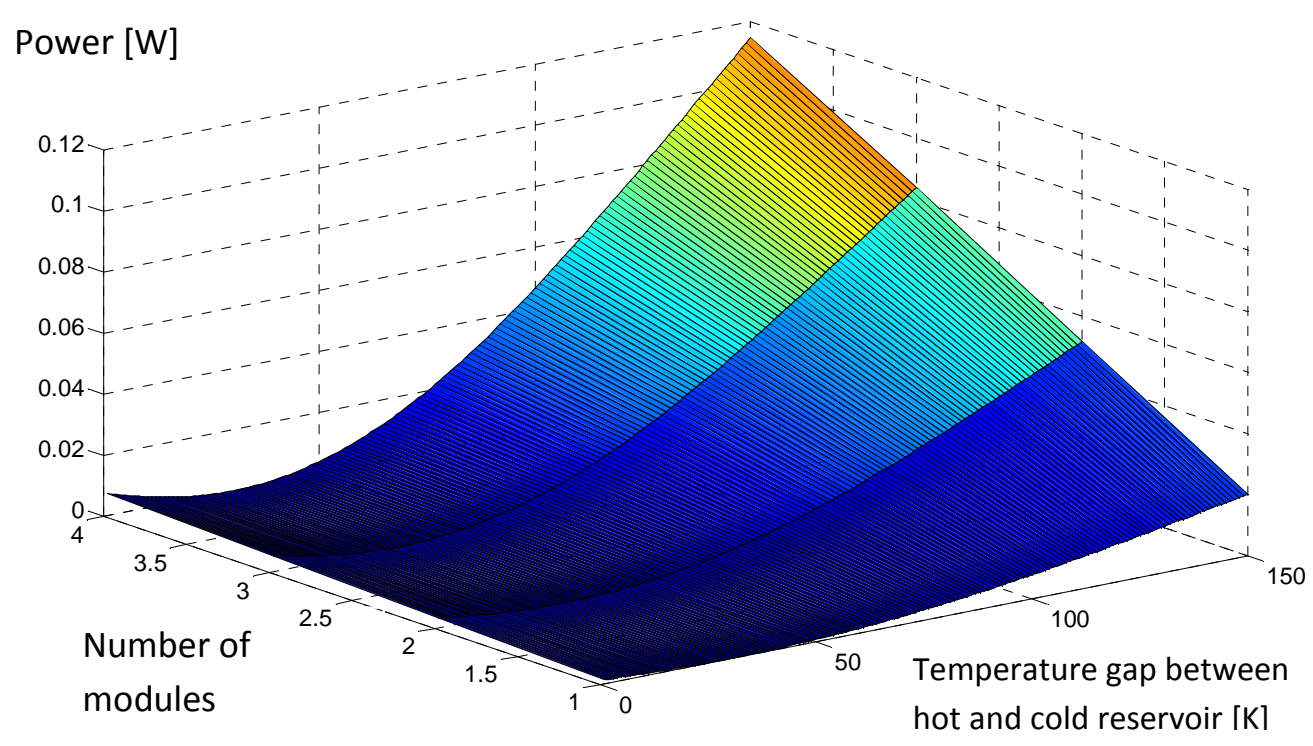

Figura 8 Power generated in the case selected $\left(\mathrm{R}_{1}=650 \Omega\right)$

The generated power ranges from 0.01 to $0.11 \mathrm{~W}$, being not enough to supply the 3 W that the Vortex Flowmeter FV4000 and its transmitter require to provide continuous information. The proposed solution involves emitting discontinuous signals instead, so 
that the electric power generated by the modules supplies continuously a rechargeable battery that is discharged from time to time to power the sensor. The energy required to emit one signal is $3 \mathrm{~J}$ and takes one second, so if the signal is sent only once every minute, $0.05 \mathrm{~W}$ of electric power is enough to store the cited $3 \mathrm{~J}$ in a battery between two subsequent emissions. As an example, Table 2 indicates that the power produced for $80{ }^{\circ} \mathrm{C}$ of temperature difference between the hot and cold reservoir is $0.0593 \mathrm{~W}$; then, a time period of $51 \mathrm{~s}$ is needed to store the $3 \mathrm{~J}$ required by the sensors and transmitters to emit one signal.

\begin{tabular}{|c|c|c|c|}
$\begin{array}{c}\text { Temperature } \\
\text { gap between hot } \\
\text { and cold [ㅇ] }\end{array}$ & $\begin{array}{c}\text { Number of } \\
\text { modules }\end{array}$ & $\begin{array}{c}\text { Thermal } \\
\text { resistance of } \\
\text { dissipater } \\
{[\text { K/W] }}\end{array}$ & $\begin{array}{c}\text { Power generated } \\
{[\mathrm{W}]}\end{array}$ \\
\hline $\mathbf{8 0}$ & 1 & 0,92 & 0,0105 \\
\hline $\mathbf{8 0}$ & 4 & 0,7 & 0,0593 \\
\hline $\mathbf{1 2 0}$ & 1 & 0.92 & 0.0201 \\
\hline $\mathbf{1 2 0}$ & 4 & 0.7 & 0.1145 \\
\hline
\end{tabular}

Table 2 Simulations with the modules connected a $R_{l}=650 \Omega$.

In this application, the thermoelectric generator would be connected to a battery, which is assumed to have a similar load resistance than the sensor (650 $\Omega$ ). One improvement would be to develop and install an electronic circuit between the modules and the battery that made the modules work at matched load. Figure 9 shows a schematic diagram of that electronic circuit, which would make the modules to feed the battery at maximum electric power. 


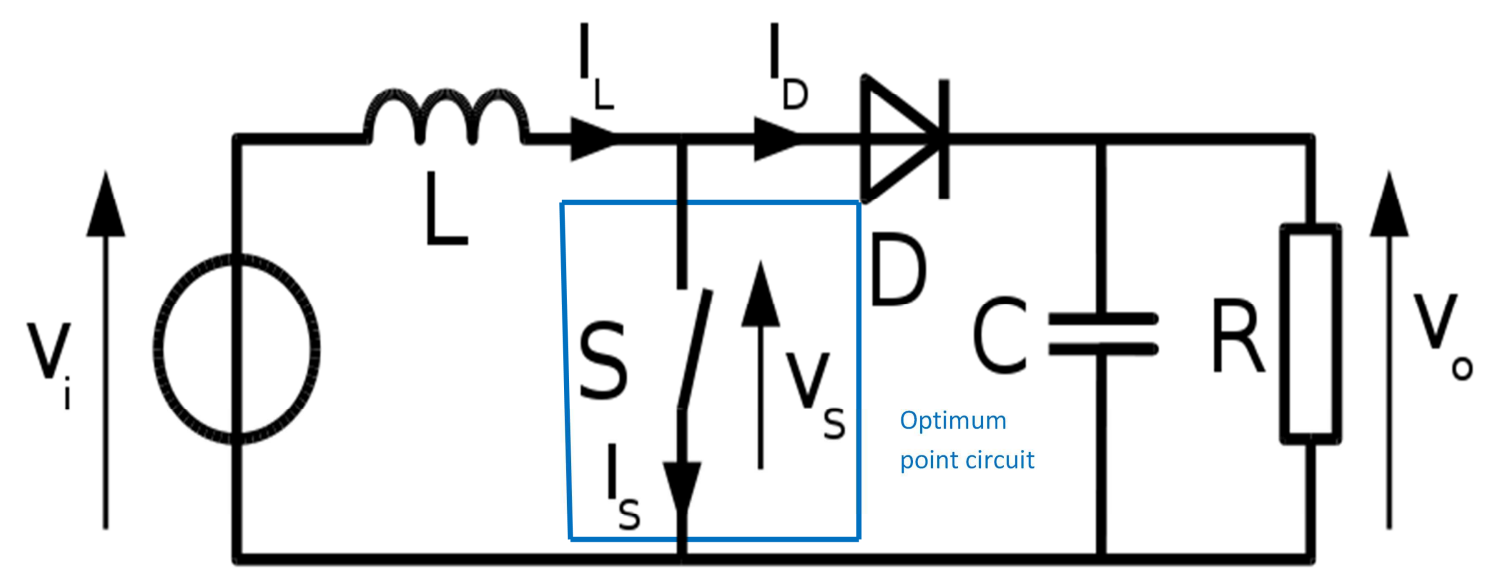

Figure 9 Electronic circuit connecting the modules to the battery.

Table 3 shows the simulations for a thermoelectric generator composed of 4 modules working in the optimum point (matched load of $16 \Omega$, when voltage is half the open-circuit voltage), with $0.70 \mathrm{~K} / \mathrm{W}$ of thermal resistance of the dissipator, and the cited electronic circuit feeding a battery of $650 \Omega$. The thermoelectric generator, in this case, could be installed in any of the selected heat sources in the plant and would produce enough power to store the required energy to operate the sensors and transmitters in a few seconds. The degasser would be the hot point for which the signal could be emitted with higher frequency, specifically each 1.64 seconds, since this is the point with the highest temperature.

\begin{tabular}{|c|c|cc|}
\hline $\begin{array}{c}\text { Temperature gap } \\
\text { between hot and cold } \\
{\left[{ }^{\circ} \mathrm{C}\right]}\end{array}$ & $\begin{array}{c}\text { Thermal resistance } \\
\text { of dissipater [K/W] }\end{array}$ & $\begin{array}{c}\text { Power } \\
{[\mathrm{W}]}\end{array}$ & $\begin{array}{c}\text { Time needed to } \\
\text { generate 3] [s] }\end{array}$ \\
\hline $\mathbf{6 0}$ & 0,7 & 0,5309 & 5.65 \\
\hline $\mathbf{8 0}$ & 0,7 & 0,8606 & 3.48 \\
\hline $\mathbf{1 0 0}$ & 0,7 & 1,203 & 2.49 \\
\hline $\mathbf{1 2 0}$ & 0,7 & 1,5284 & 1.96 \\
\hline $\mathbf{1 4 0}$ & 0,7 & 1,831 & 1.64 \\
\hline
\end{tabular}

Table 3 Simulations with the modules connected a $R_{1}=16 \Omega$. 


\section{Conclusions}

Several sources of waste heat in a biomass power plant have been examined to serve as heat sources for thermoelectric generators intended to supply electric power to autonomous and independent sensors. The most interesting are the chimney $\left(127{ }^{\circ} \mathrm{C}\right.$ between the heat source and the environment), the smoke filter $\left(127^{\circ} \mathrm{C}\right)$, the ignition air flow $\left(70{ }^{\circ} \mathrm{C}\right)$ and the degasser $\left(140^{\circ} \mathrm{C}\right)$. In parallel, a thermoelectric generator has been designed and studied. This methodology includes Ansys-Fluent simulations to calculate the thermal resistance of the finned dissipator, which ranges from 0.70 to $0.92 \mathrm{~K} / \mathrm{W}$ depending on the number of modules installed in the thermoelectric generator.

Finally, a computational model has been used to assess the influence of various factors on the electric power generated. The first conclusion indicates that both the thermal resistance of the dissipator and the load resistance are the most influential factors, so that a little increase in any of them reduces dramatically the electric power produced by the thermoelectric generator. Secondly, an increasing number of modules always lead to an increase in the electric power. Finally, the best option is to use multiple modules per dissipator, thus reducing cost and eliminating the problems associated with space availability.

The thermoelectric generator is not capable of feeding continuously a Vortex flowmeter FV4000 and its corresponding transmitter ELSELMA FV4000 TXA15101E, but the electric power could be stored in an intermediate battery that allows emitting a signal every minute.

Finally, we have developed an electronic circuit that allows the generator to work at optimum power and increase the electric power supplied to the battery. Thanks to this electronic circuit, the time required to charge the battery and emit signals was reduced to less than 5 seconds. 


\section{Acknowledgments}

The authors are indebted to the Spanish Ministry of Science and Innovation (DPI2011-24287) and FEDER funds (European Union) for the economic support to this work

\section{References}

[1] Akai S., Takeda S., Onuma Y., Kobayashi M. (1985), "Thermoelectric properties of deposited semiconductor films and their application”, Electrical Engineering in Japan, v. 105, pp. 1-8.

[2] Hara T., Azuma H., Shimizu H., Obora H., Sato S. (1998), “Cooling performance of solar cell driven thermoelectric cooling prototype headgear", Applied Thermal Engineering, v. 18, pp. 1159-69.

[3] Lazarenko Y.V., Gusev V.V., Pustovalov A.A., Zhabin V.N. (1989), "Pu238-based smallsize RTG for artificial heart systems and assisted blood circulation systems", Proceedings of the XXIV Intersociety Energy Conversion Engineering Conference, v. 6, pp. 2785-8.

[4] http://www.enerkit.com/2/upload/2012_enerkit_modules.pdf, Accesed June, 2012.

[5] Rodríguez A., Vián J.G., Astrain D., Martínez A. (2009) "Study of thermoelectric systems applied to electric power generation.”, Energy Conversion and Management. 50/5, pp. 12361243

[6] Rodríguez A., Vián J.G., Astrain D. (2009) "Development and experimental validation of a computational model in order to simulate ice cube production in a thermoelectric ice maker", Applied Thermal Engineering. 29, pp. 2961-2969

[7] D. Astrain, J. G. Vián, A. Martínez, A. Rodríguez. (2009) "Study of the influence of heat exchangers' thermal resistances on a thermoelectric generation system", Energy, 35, pp.602-610

[8] Bell L.E. (2008), Cooling, heating, generating power, and recovering waste heat with thermoelectric systems, Science, v. 321, pp. 1457-61.

[9] Kajikawa T. (2006), Thermoelectric Power Generation System Recovering Industrial Waste Heat, en Rowe D.M. Thermoelectrics Handbook. Macro to Nano ( $1^{\mathrm{a}} \mathrm{ed}$.), CRC Press, Boca Raton, pp. 50.1-50.26.

[10] Rowe D.M. (2006), General Principles and Considerations, en Rowe D.M.,Thermoelectrics Handbook. Macro to Nano ( $1^{\mathrm{a}}$ ed.), CRC Press, Boca Raton, pp. 1.1-1.14.

[11] Astrain D. (2003), "Increase of COP in the thermoelectric refrigeration by the optimization of heat dissipation", Applied Thermal Engineering. 23, 17 pp. 2183-2200 
[12] Yovanovich, M. M. Muzychka, Y. S. Culham, J. R. (1999), Spreading resistance of isoflux rectangles and strips on compound flux channels. Journal of Thermophysics and Heat Transfer, 13 , pp 495-500

\section{$\underline{\text { Figure captions }}$}

Fig. 1 Scheme of the biomass power plant

Fig. 2 TEG localization in different components of the plant

Fig. 3 Scheme of the thermal-electric analogy of the computational model.

Fig. 4 Power generated as a function of the Rd and R1

Fig. 5 Power generated as a function of the number of modules and $\mathrm{Rl}, \quad(\mathrm{Rd}=$ $0.23 \mathrm{~K} / \mathrm{W})$.

Fig. 6 Configurations proposed for the dissipator

Fig. 7 Power generated as a function of the number of modules and $\mathrm{Rl},(\mathrm{Rd}=0.7 \mathrm{~K} / \mathrm{W})$.

Fig. 8 Power generated in the case selected $\left(\mathrm{R}_{1}=650 \Omega\right)$

Fig. 9 Electronic circuit connecting the modules to the battery

\section{$\underline{\text { Table captions }}$}

Table 1 Temperature drop of the working fluid, $\Delta \mathrm{T}_{\mathrm{i}}$, for different configurations

Table 2 Simulations with the modules connected a $\mathrm{R} l=650 \Omega$.

Table 3 Simulations with the modules connected a $R_{1}=16 \Omega$. 